\title{
EL VALLE MEDIO DEL EBRO COMO ZONA DE CONTACTO LINGÜÍSTICO DE LAS LENGUAS PALEOHISPÁNICAS ${ }^{1}$
}

\author{
CARlos Jordán Cólera* \\ Universidad de Zaragoza
}

\begin{abstract}
Resumen
Los datos históricos, arqueológicos y lingüísticos demuestran que el Valle Medio del Ebro fue una zona donde convivían una serie de pueblos prerromanos que hablaban cuando menos tres variedades lingüísticas diferentes: el celtibérico, lengua indoeuropea celta; el ibérico, lengua genéticamente aislada; y el vascón, lengua también genéticamente aislada. En este artículo, se estudia parte del material directo dejado por esos pueblos, así como material epigráfico latino, para analizar posibles interferencias lingüísticas entre las cuatro lenguas en contacto (celtibérico, ibérico, vascón y latín).
\end{abstract}

Palabras clave: interferencia lingüística, lenguas en contacto, celtibérico, ibérico, vascón y latín.

\section{Abstract}

Historical, archaeological and linguistic data show that the Middle Ebro Valley was an area where different pre-roman ethnic groups lived in contact. These tribes spoke at least three different linguistic varieties: Celtiberian, a Celtic Indo-European language; Iberian, a genetically isolated language, and Vascon, another genetically isolated language. In this article, the author studies part of the direct material left by these peoples, as well as the Latin epigraphic material, in order to analyze possible linguistic interferences between the four languages in contact (Celtiberian, Iberian, Vascon and Latin).

Key Words: Linguistic interference, languages in contact, Celtiberian, Iberian, Vascon and Latin.

${ }^{1}$ Este texto viene a reproducir con leves modificaciones y añadidos la ponencia titulada El Valle del Ebro como zona de contacto de las lenguas paleohispánicas, presentada por el autor en la Sesión Plenaria vespertina del día 18 de diciembre de 2007 en el XXXVII Simposio Internacional de la Sociedad Española de Lingüística, celebrado en la Universidad de Navarra, en Pamplona. Queremos manifestar nuestro más sincero agradecimiento a la Junta Directiva de la Sociedad y al Comité Organizador del evento por habernos invitado a participar en él. Este trabajo hay que entenderlo como fruto de nuestra participación en el Proyecto de Investigación Identidades y diversidad cultural en la Historia Antigua: Bilingüismo y Cultura Epigráfica (Hum 2006-13424-CO4-02/Filo), cuyo investigador principal es el Dr. F. Beltrán Lloris, de la Universidad de Zaragoza.

* A mi hermana Fina y mis sobrinos Ernesto, Carmen y Manuel, mi familia «de Pamplona». 


\section{INTRODUCGIÓN}

La llegada de los romanos a la Península Ibérica tuvo lugar oficialmente en el año 218 a.e. en el marco de la II Guerra Púnica. Los Escipiones venían a hacer frente a Aníbal, pero éste ya había sometido la costa mediterránea de la península camino de Italia. Cuando los romanos desembarcan en Ampurias, además de por los cartagineses, la península estaba habitada por otros pueblos.

Todos estos pueblos son prerromanos desde el punto de vista cronológico. Ahora bien, si se tiene en cuenta el lugar donde ha tenido o se cree que ha tenido lugar el desarrollo y floruit cultural de esos pueblos, se distingue entre pueblos paleohispánicos y los que no lo son. Los primeros, los paleohispánicos, son endógenos culturalmente hablando, sus culturas se desarrollaron y llegaron a su cénit en la Península Ibérica, independientemente de la causa y el momento en que llegaran aquí. Son, en definitiva, pueblos indígenas. Los segundos son exógenos, sus culturas ya habían conocido su apogeo en otro hábitat diferente y vienen aquí con pretensiones en principio puramente comerciales. Son pueblos coloniales. Entre estos últimos hay que contar a fenicios y cartagineses, que no dejan de ser sus continuadores y herederos, y a los griegos. Entre los pueblos paleohispánicos se encuentran los celtas, iberos, vascones y otros pueblos que no se conocen o no se sabe nominar.

Cuando fenicios y griegos llegaron a la Península Ibérica y establecieron sus factorías y colonias, contaban ya con unos sistemas de escritura propios y hacían uso de ellos: el alfabeto fenicio y el griego. A estos sistemas de escritura se les denomina, precisamente, «escrituras coloniales». No hará falta recordar que los griegos aprendieron a escribir de los fenicios: adoptaron y adaptaron su sistema de escritura.

Entre los pueblos paleohispánicos los hubo ágrafos. A lo largo de la cornisa cantábrica, buena parte de la meseta y el territorio hasta Sierra Morena, más o menos, se extiende un territorio vacío de escritura. Las fuentes clásicas hablan de diferentes pueblos: várdulos, cántabros, ástures y galaicos en la cornisa; vacceos, vetones y carpetanos en la meseta, que evidentemente tendrían sus respectivas lenguas. Sin embargo, la información que existe al respecto hay que extraerla de la documentación indirecta: de la epigrafía latina y los autores clásicos.

Y hubo pueblos paleohispánicos que utilizaron la escritura. Unos crearon sus sistemas de escritura in situ y lo hicieron, según parece, adoptando y adaptando los dos alfabetos referidos, con preminencia, se acepta, del fenicio. Se trata del pueblo o pueblos responsables de la denominada asépticamente «lengua del suroeste», para algunos el «tartesio»; los pueblos que hablaban y escribían lo que se llama ibérico; y los pueblos que hablaban y escribían lo que se designa como celtibérico. Si se exceptúan el alfabeto greco-ibérico, resultado de adaptar el alfabeto 
griego a la lengua ibérica en una zona bastante concreta del levante español (entre las provincias de Alicante y Murcia), el resto de escrituras paleohispánicas, que se engloban bajo la denominación de «signario paleohispánico», son sorprendentemente semi-silabarios.

Dentro de este grupo de pueblos paleohispánicos con expresión escrita hay que hacer referencia al caso del responsable de la lengua que en la actualidad se denomina de manera general lusitano y que entró en la historia utilizando directamente el alfabeto latino. La escasísima documentación que se posee de esta lengua, cuatro inscripciones que se fechan en los siglos I-II d.e. (una de las cuales está perdida desde el siglo XVIII y es conocida sólo por calcos y otra es una laja de piedra con apenas seis palabras), muestra dos casos de inscripciones mixtas latín-lusitano (transcripción según Untermann 1997):

[L.1.1] : Arroyo de La Luz (Cáceres, España): AMBATVs / SCRIṔsi / CARLAE PRAISOM / SECIAS.ERBA.MVITIE / AS.ARIMO.PRAESO/NDO.SINGEIE*O / INDI.AVA.INDI.VEA/VN.INDI.*EDAGA/ROM.TEVCAECOM / INDI.NVRIM.I** / VDE*EC.RVRSE*CO / AMPILVA / INDI / GOEMINA.INDI.ENV/PETANIM.INDI. AR/IMOM.SINTAMO/M.INDI.TEVCOM / SINTAMO [L.2.1] Lamas de Moledo (Portugal): RVFInVS.ET / TIRO SCRIP/SERVNT / VEAMNICORI / DOENTI / ANGOM / LAMATICOM / CROVCEAIMAGA/REAICOI. PETRANEIOI.T / ADOM.PORGOMIOVA./ CAELOBRIGOI

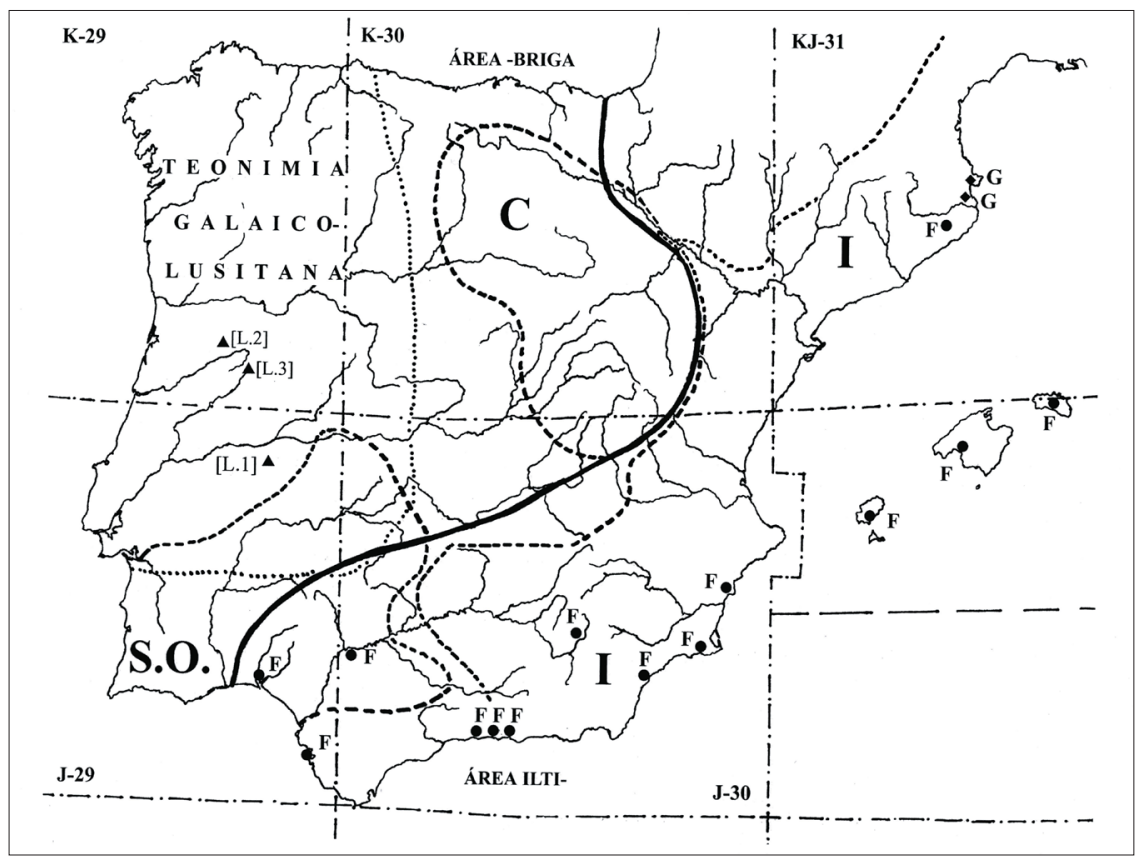




\begin{tabular}{|c|c|c|c|}
\hline & Lengua & Sistema de escritura & Clasificación lingüística \\
\hline $\mathrm{F}$ & \begin{tabular}{|l} 
fenicio \\
púnico \\
libio-fenicio
\end{tabular} & $\begin{array}{l}\text { - alfabeto fenicio } \\
\text { y variantes }\end{array}$ & familia semita \\
\hline G & griego & - alfabeto griego & $\begin{array}{l}\text { familia indoeuropea } \\
\text { sub-familia griega }\end{array}$ \\
\hline I & ibérico & $\begin{array}{l}\text { - signario paleohispánico } \\
\text { ibérico sur- y nor-oriental } \\
\text { - alfabeto greco-ibérico } \\
\text { - alfabeto latino }\end{array}$ & no-indoeuropea \\
\hline C & celtibérico & $\begin{array}{l}\text { - signario paleohispánico } \\
\text { - alfabeto latino }\end{array}$ & $\begin{array}{l}\text { familia indoeuropea } \\
\text { sub-familia celta }\end{array}$ \\
\hline S.O. & $\begin{array}{l}\text { lengua del } \\
\text { S.O. } \\
\text { o tartésico } \\
\end{array}$ & $\begin{array}{l}\text { - signario paleohispánico } \\
\text { del S.O. }\end{array}$ & $\begin{array}{l}\text { ¿familia indoeuropea? } \\
\text { ¿sub-familia celta? }\end{array}$ \\
\hline $\mathrm{L}$ & lusitano & - alfabeto latino & $\begin{array}{l}\text { familia indoeuropea } \\
¿ \text { ¿sub-familia? }\end{array}$ \\
\hline
\end{tabular}

La cuenca media del Ebro constituye una región natural con unos límites bastante bien definidos: los Pirineos al norte, la cadena costerocatalana al este, el sistema Ibérico y el estrechamiento del Valle en La Rioja al sur y oeste (Beltrán 2006, p. 218). Fatás 1998 definió el Ebro medio como un «trifinio paleohispánico». Por utilizar sus propias palabras, ibid. p. 32:

El trifinium, en latín, es el lugar en el que confluyen tres fines o fronteras (confines, decimos aún)... En este trifinio hispánico que es el Ebro medio coinciden y se tocan largamente, y sólo en él, lo vascónico (por los váscones o vascones; y por lo vasco propiamente dicho), lo ibérico y lo indoeuropeo (en la variedad céltica).

Para saber cómo se tocan lingüísticamente esos tres dominios, hay que tener presente que se van a manejar lenguas de corpus fragmentariamente testimoniadas. Esta expresión viene a traducir el contundente compuesto alemán Trümmersprachen 'lenguas en ruinas'. En efecto, el conocimiento de sus gramáticas es ruinoso, pues hay que extraerlo de unos corpora epigraphica muy, muy limitados. Tan limitados que se hace indispensable conocer el concurso del cuarto dominio lingüístico que se superpuso a los tres anteriores, el latino, y aún así, según habrá ocasión de comprobar, en algún caso parece que se está ante lenguas «incorpóreas». Hay que subrayar que el estudio lingüístico necesita del epigráfico, numismático, arqueológico e histórico. En esta relativamente joven disciplina de la paleohispanística se intenta practicar no sólo la multidisciplinariedad, sino también la interdisciplinariedad. 
Si se conjugan los datos que aporta la documentación directa, es decir, lo escrito en esas lenguas paleohispánicas, con los de la indirecta de o sobre la zona, el resultado que se obtiene es uno en la margen derecha y otro muy diferente en la izquierda del Valle. Si se parte desde Vareia, junto a la actual Logroño, hasta la zona de desagüe del Matarraña, más o menos en la frontera entre Zaragoza y Teruel con Tarragona, en la margen derecha la documentación directa es relativamente abundante y cumple con unos requisitos de variedad y coexistencia de tipos de textos que basta para delimitar, en principio, dos áreas epigráficas bastante bien definidas y complementarias, contiguas geográficamente, que se corresponden con dos áreas lingüísticas: el área celtibérica (indoeuropea y en concreto celta) y el área ibérica (lengua sin parentescos genéticos claros). El área ibérica no se para en la zona indicada, sino que sigue hasta la costa y salta a la margen izquierda ocupando parte del Aragón oriental y toda la actual Cataluña. En la margen izquierda, en cambio, partiendo desde Vareia hasta la altura del Cinca, esa documentación es escasa, realmente pobre, y muy difícil de valorar no sólo epigráfica, sino también lingüísticamente. El recurso a la documentación indirecta ofrece material lingüístico celta, ibérico y vascón, pero sin poder establecer unas áreas epigráfico-lingüísticas, como al otro lado del Ebro.

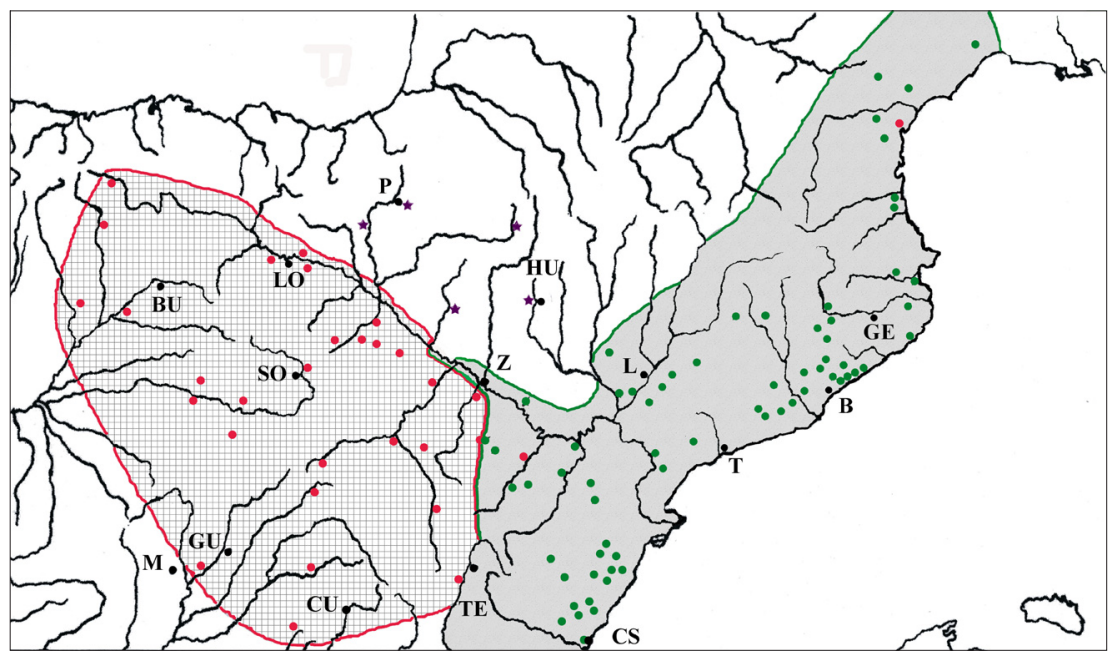

Mapa 2: Áreas epigráfico-lingüísticas en el Valle del Ebro. La zona con retícula es la celtibérica, la sombreada la ibérica. Los puntos y estrellas indican lugares de hallazgos epigráficos. Están indicadas las capitales de provincia actuales: $\mathrm{P}=$ Pamplona, $\mathrm{LO}=$ Logroño, $\mathrm{BU}=$ Burgos, $\mathrm{SO}=$ Soria, GU = Guadalajara, $\mathrm{M}=$ Madrid, $\mathrm{CU}=$ Cuenca, $\mathrm{TE}=$ Teruel, $\mathrm{Z}=$ Zaragoza, HU = Huesca, $\mathrm{L}=$ Lérida, GE = Gerona, B = Barcelona, $\mathrm{T}=$ Tarragona, $\mathrm{CS}=$ Castellón. 


\section{MARgen Derecha}

El área epigráfico-lingüística celtibérica se extiende entre las cabeceras de los ríos Duero, Tajo, Júcar y Turia, hasta el nacimiento del río Martín, por el oeste, sur y este; y, por el norte, el curso medio del Ebro, con una frontera paralela a su margen derecha a una decena de kilómetros que pasa al otro lado del río en la zona colindante entre las actuales Navarra y Aragón.

Hoy en día se utiliza el etnónimo "celtíbero» como glotónimo para referirse a la lengua paleohispánica recogida en los documentos hallados, de momento, en los territorios de los belos, titos, lusones, arévacos, pelendones y berones. Ésta es la única lengua paleohispánica testimoniada sobre cuya celticidad nadie duda. Y en este sentido quizá pueden ser equiparables los términos «hispano-celta» y «celtibérico» (Villar 1999, p. 74). Sin embargo, a estas alturas, nadie duda de que hubo más hablantes de lenguas celtas en la Península Ibérica (con seguridad en la meseta y en la fachada atlántica, e incluso en el extremo suroccidental de la península). La existencia de este continuum lingüístico celta peninsular es razón suficiente para reservar el término «hispano-celta» o, de manera alternativa, "celta de la Península Ibérica», que incluso parece más correcto, para ese conjunto de hablas celtas hispanas y no equiparlo sin más al de «celtibérico».

Estos testimonios presentan una cronología que abarca los siglos II y i a.e. y se hallan escritos en signario paleohispánico y alfabeto latino. El repertorio en lengua celtibérica cuenta en la actualidad con unas 60 leyendas monetales diferentes, que corresponden a una treintena de cecas; un centenar largo, que va creciendo día a día, de epígrafes sobre instrumentum domesticum, la mayoría sobre cerámica, aunque hay tres sobre vajilla de plata; 10 epitafios; una treintena de téseras de hospitalidad en bronce y alguna en plata; 6 plaquitas de bronce; 3 tabulae de bronce; y una veintena de grafitos rupestres.

El área epigráfico-lingüística ibérica recorre ese pasillo de la margen derecha del Ebro desde la zona colindante entre las actuales Navarra y Aragón, al que se ha hecho alusión con anterioridad; se va abriendo poco a poco y desciende hacia el sur una vez pasada la población de Belchite (Zaragoza), hasta llegar al nacimiento del río Martín; desde allí desciende hacia la ciudad de Teruel y sigue, ya fuera del espacio geográfico que aquí interesa (el Valle Medio del Ebro) por el límite de la actual provincia de Valencia, hacia el sur, ocupando las de Alicante, Murcia, Albacete, Jaén, Almería y Córdoba. El dominio epigráfico-lingüístico también se extiende por la margen izquierda del río Ebro, en paralelo al corredor de la margen derecha, que se abre hacia el norte en dirección del río Cinca y la Noguera-Ribagorzana (aunque v. al final 
de este trabajo la posible variación de esta frontera a partir de la documentación indirecta y el reanálisis de alguna leyenda monetal). A partir de este río se encuentra de nuevo una zona ibérica homogénea desde el punto de vista epigráfico-lingüístico en zona catalana. Los Pirineos no son un obstáculo para que el dominio ibérico se extienda por suelo francés, siguiendo la costa, hasta llegar al valle del río Hérault.

En esta vasta extensión, la documentación ibérica abarca una horquilla temporal que va desde el siglo v a.e. a los siglos I-II d.e. Es rica en soportes y metales: plomo, plata y bronce; piedra; cerámica; hueso, etc. También son variados los tipos de documentos: documentos comerciales, textos mágico-religiosos, inscripciones sepulcrales, monedas, grafitos sobre instrumentum domesticum, inscripciones musivarias, etc. (Velaza 1996, pp. 24-29). El ibérico aparece escrito en cuatro sistemas de escritura:

- Signario paleohispánico nororiental, en el sur de Francia, Cataluña, Aragón, Castellón y Valencia.

- Signario paleohispánico suroriental, a lo largo de las provincias de Alicante, Murcia, Albacete, Jaén, Almería y Córdoba, sobre todo en las zonas castulonense (Valle alto del Guadalquivir, especialmente en Obulco y Castulo, provincia de Jaén) y contestana (costa de Alicante y Murcia).

- Alfabeto griego (la provincia de Alicante y norte de Murcia).

- Alfabeto latino, de forma muy escasa, como en [G.12.4] Alcudia (Elche, Alicante), por ejemplo.

Por lo que se refiere al Valle Medio del Ebro, la cronología de la documentación ibérica se extiende a lo largo de los siglos in y i a.e. y está escrita en signario paleohispánico nororiental. Hay leyendas monetales, sobre instrumentum domesticum y epitafios. Existen dos inscripciones musivarias de las que se hablará, que se han hallado, sin embargo, en territorio celtibérico (Caminreal, Teruel) y en la margen izquierda del Ebro, en concreto en Muruzábal de Andión, Navarra.

A día de hoy, la lengua ibérica sigue sin ser descifrada. Es una lengua aislada genética y tipológicamente.

Aunque cada una tenga unas particularidades propias, las áreas epigráficas celtibérica e ibérica en el Valle Medio del Ebro no son dos áreas epigráficas independientes, sino que conforman un continuum debido a dos razones:

$1^{\underline{a}}$ Los celtíberos adoptaron y adaptaron el sistema de escritura nordoriental ibérico para escribir su lengua. Evidentemente, esto debe ser fruto de contactos culturales habidos antes y durante el siglo II a.e.

$2^{2}$ La mayor parte de su expresión escrita es co-romana, esto es, los hablantes de estas lenguas de la zona del Valle Medio del Ebro 
van a adoptar del mundo romano que entra en contacto con ellos la necesidad de plasmar por escrito una serie de datos que hasta ese momento no necesitaban indicar. En segundo lugar, adoptan su tipología documental: monedas, inscripciones funerarias, inscripciones musivarias, téseras de hospitalidad, tabulae de bronce... Y en tercer lugar la cronología de esa documentación abarca los siglos II y i a.e.

Como indica Beltrán 1995, p. 181:

La difusión de la escritura y de la expresión epigráfica en el valle medio del Ebro es fruto de un doble proceso de aculturación ibérico y romano, en parte sucesivo y en parte simultáneo, que afecta de manera diversa a las diferentes comunidades étnicas según su estructura social, su tradición cultural y sus relaciones con Roma.

Según la documentación que existe hoy en día de las lenguas celtibérica e ibérica, parece que los contactos entre ambas comunidades no tuvieron una repercusión lingüística. Al menos no se ha sabido detectar hasta el momento ningún caso de transferencia lingüística, sensu lato. Otra cuestión es encontrar palabras de una lengua en documentos escritos en la otra. En todo caso son «cambios de código", en inglés code-switching, pero un tanto especiales, pues se trata de indicaciones antroponímicas.

Así, en el Tercer Gran Bronce de Botorrita [K.1.3], documento escrito en lengua celtibérica (con unas medidas de 73,2 x 51,8 x 0,4 $\mathrm{cm}$.), entre unas doscientas fórmulas onomásticas, aparecen los siguientes antropónimos ibéricos, a juicio de Untermann (en Beltrán, De Hoz y Untermann 1996). En el presente trabajo se sigue la convención de transcripción de los Monumenta Linguarum Hispanicarum para las diferentes modalidades del signario paleohispánico, esto es, en minúsculas y negrita. (En la lista siguiente las formas en cursiva son los posibles antropónimos ibéricos. Una cruz indica un signo ilegible parcialmente conservado; [.] es un signo perdido; los dos puntos indican una interpunción; las letras subrayadas son signos de lectura insegura):

\begin{tabular}{|c|c|}
\hline I 37 & biurtilaur: alaskum \\
\hline I $40-41$ & or++bilos: likinoskue / abo++kum \\
\hline I 49 & iunsti+[.]: uiriaskum \\
\hline I 59 & barnai: turumokum : tirs \\
\hline II 44 & toloku: kalisokum : atinos \\
\hline II 45 & tarkunbiur \\
\hline II 50 & bartiltun: ekarbilos \\
\hline III 5 & toloku: koitinakue : austunikum \\
\hline III 17 & barnai: ensikum : skirtunos \\
\hline III 20 & toloku: uiriaskum \\
\hline IV 26 & toloku: kurmi+iokum \\
\hline
\end{tabular}


IV 27 anieskor: talukokum

IV 34 bilosban: betikum

Aunque en algún caso se pueda dudar de su ibericidad lingüística, en otros es bastante difícil hacerlo. Por ejemplo: para biur-tilaur, cf. tarkun-biur; para ekar-bilos, cf. bilos-ban y or++bilos. bartiltun se analiza como bart-iltun. Esta segmentación no es aleatoria, pues los componentes aislados se corresponden con elementos antroponímicos ibéricos detectados en el mismo documento o en otros. Se volverá sobre este asunto más adelante.

Otra cuestión es saber qué hacen allí estos personajes con antropónimos ibéricos. La clave está probablemente en las dos primeras líneas del documento, las cuales todavía no se han sabido traducir:

01 risatioka : lestera $:$ ia : tarakuai : nouiza : auzanto

02 eskeninum : taniokakue : soisum : albana

El día que se desentrañen se sabrá qué hacían esas personas en la lista, de la misma forma que se averiguará el papel que tendrían las que presentan antroponimia griega:

I 1 skirtunos : tirtanikum : 1(-)

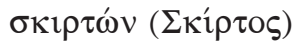

I 20 bilinos: austikum

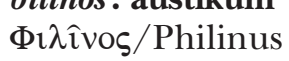

I 50 tioken+s : uiriaskum

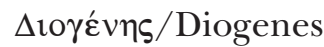

II 31 tais: uiriaskum

Oxis/Thais

III 9 antiokos: uiriaskum : $\operatorname{melm}(-)$

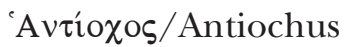

III 28 bilonikos: elokum : elkinos

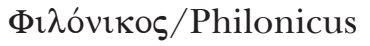

III 51 bilonikos: ensikum

IV 4 tiokenesos: uiriaskum

IV 13 antiokos: kustikum

Y los que la presentan latina:

I 32 saluta: uizuskikum

Saluta

IV 3 bolora : kentiskue : melmanzos

Flora

IV 18 balakos: sekonzos

Flaccus

IV 22 bubilibor: uiriaskum

Publiplor 
En todos o casi todos los casos, los antropónimos, tanto ibéricos, como griegos y latinos, están insertos en fórmulas onomásticas típicamente celtibéricas, en las que al idiónimo sigue el genónimo, es decir, el nombre del grupo familiar al que pertenecían, como por ejemplo: biurtilaur alaskum 'Biurtilaur del grupo familiar de los Alascos'; e incluso puede aparecer el tercer miembro de la fórmula, el patrónimo: barnai turumokum tir(tuno?)s 'Barnai del grupo familiar de los Turumocos, hijo de ¿Tritón?’. Parece que hay algún caso de fórmula ibérica: bartiltun ekarbilos = idiónimo + patrónimo, que es la que por cierto presentan los otros celtas continentales, galos y lepónticos. Es este un rasgo cultural que diferencia a los celtíberos de sus «hermanos» continentales.

El celtíbero que escribió o mandó escribir este documento parece que no tuvo problemas en adoptar los antropónimos latinos y griegos a los patrones morfológicos de su lengua: temas en -o (bilinos, bilonikos, antiokos, balakos), en - $a$ (saluta, bolora), en - $n$ (skirtunos, en genitivo), en $-s$ (tiokenes pero tiokenesos), en $-r$ (bubilibor), en dental (tais). Sin embargo, a la hora de escribir los antropónimos ibéricos no parece esforzarse en adaptarlos a su lengua: barnai, biurtilaur, bartiltun, ekarbilos, que si está en posición de patrónimo debería ir en genitivo, *bilo, pero el formante es bilos. No está, pues, declinado.

En este aspecto parece que tuvo el mismo problema que el escritor del Bronce de Ascoli. En 1908, se halló en esa localidad italiana una tabula de bronce de 29 por $51 / 52 \mathrm{~cm}$., escrita en latín, en la que Cneo Pompeyo Estrabón concedía la ciudadanía romana a treinta equites de la turma salluitana, con motivo de su valor demostrado durante la guerra social. Este documento sirvió a M. Gómez Moreno, a comienzos del siglo $\mathrm{xx}$, para sentar las bases del conocimiento moderno de la formación de la antroponimia ibérica. Un antropónimo ibérico «ortodoxo» se compone de dos miembros que denominamos formantes antroponímicos, cada uno de los cuales consta de dos sílabas. Estos formantes antroponímicos pueden aparecer tanto en primera posición como en segunda.

Según se lee en el documento, fechado el 89 a.C. casi contemporáneo, pues, al tercer gran bronce, los caballeros en cuestión se llamaban:

Turma Salluitana: Sanibelser Adingibas f., Illurtibas Bilustibas f., Estopeles Ordennas f., Torsinno Austinco $f$.

Bagarensis: Cacususin Chadarf.

JUcenses: ] Sosimilus f., JIrsecel f., JElgaun f., ]Espaiser f.

Ilerdenses: Q. Otacilius Suisetarten f., Cn. Cornelius Nesille f., P. Fabius

Enasagin $f$.,

Begensis: Turtumelis Atanscer f.,

Segienses: Sosinaden Sosinasae f., Sosimilus Sosinasae f., Urgidar Luspanar

$f$., Gurtarno Biurno $f$., Elandus Enneges f., Agirnes Bennabels $f$., Nalbeaden Agerdo f., Arranes Arbiscar f., Umargibas Luspangib(as) $f$.

Ennegenses: Beles Umarbeles f., Turinnus Adimels f., Ordumeles Burdof.

Libenses: Bastugitas Adimels f., Umarillum Tarbantu f. 
Suconenses: Belennes Albennes f., Atullo Tautindals $f$. Illuersensis: Balcidadin Balcibil f.

De las ciudades nombradas mediante sus localicios, tan sólo están bien localizadas Salluie $=$ Zaragoza, Segia $=$ Ejea de los Caballeros $(Z)$ e $I l e r d a=$ Lérida. Las demás parece que deberían encontrarse también en la margen izquierda del Ebro entre las provincias de Lérida, Huesca, Zaragoza y quizá, aunque más difícil, Navarra.

En el documento hay claros antropónimos latinos, en fórmulas latinizadas con praenomen y nomen, entre los ilerdenses, explicables fácilmente por la pronta conquista de iltirta/Ilerda/Lérida por parte romana, hacía entonces un siglo aproximadamente: Quintus Otacilius, Cnaeus Cornelius y Publius Fabius, todos temas de la segunda declinación en nominativo, cuyos padres siguen conservando el idiónimo ibérico: Suisetarten, Nesille y Enasagin.

Quizá haya antropónimos celtas como Elandus y Atullo, temas en -o y en $-n$, bien declinados, al ser nominativos. Elandus puede relacionarse con Elando de CIL I2 2825 H F cum Elandorian (Cáceres), con Elandetus de Jarandilla de la Vera CC y elatunako [K.9.4] numantino. El paralelo más claro de Atullo es el celtibérico atulikum [K.0.6].

Más extraño es el caso de Burdo y Tarbantu. Para el primero hay perfectas correspondencias celtas, como Burdo, -onis, en las Galias, el norte de Italia y Britania. En la Península Ibérica, en [K.1.3, I.23, 26, 33, 47, 54; II.10, 41; III.7, 14; IV.6, 7] aparece burzu, además del antropónimo Burdo Medugeno que dieron a conocer Beltrán y Ortiz 2002 en una cotícula conservada en el Museo de Zaragoza. Parece que presenta una terminación latina de nominativo singular de tema en nasal, pero está en posición de genitivo. En cuanto a Tarbantu, tiene apariencia de una formación a partir de *taurum, con la metátesis que se da en las lenguas celtas y no es extraño en la antroponimia, comenzando por Tó $\rho \beta o v, T a-$ ruenus, Taruillus, etc., junto a Donnotaurus, Taurina, etc., en galo. En celtibérico aparece tarvoture[.]ka [K.23.2] y TARVODVRESCA [CT-2A], pero tauro en [K.1.1, B7 y 8]. La terminación en -u apunta en todo caso a un patrón celtibérico de nominativo singular de tema en nasal, pero también está en posición de genitivo. ¿Son iberos con antroponimia celta más o menos latinizada, pero sin variación morfológica por estar ya incrustados en una fórmula ibérica? Ambos antropónimos, no obstante, son considerados ibéricos por Untermann 1990, con un primer elemento bor- y tarban- y unos sufijos -to y -tu.

El resto de los antropónimos son bien identificables como ibéricos. Algunos de ellos ni tienen correspondencia con patrones morfológicos latinos, ni están adaptados al latín, como por ejemplo los padres de los caballeros ilerdenses: Suisetarten, Nesilley Enasagin. En otros casos, las terminaciones de algunos de ellos coinciden con las de algunos patrones morfológicos latinos. Pero es que aunque coincidan esos patrones, el simple análisis del texto permite observar que el grabador no se atrevió a declinarlos. Hay una prueba bastante evidente: aparece un segiense 
que se llama Sosimilus Sosinasae f. El idiónimo parece un tema en -o, pero hay una persona perteneciente a los Jucenses cuyo patrónimo es el mismo ] Sosimilus $f$. Parece que la forma le llegó latinizada de origen, pues el antropónimo en cuestión está conformado por sosin + bilos, y no se atrevió a declinarla, porque resulta extraño que no supiera identificarla como tema en - 0 . De hecho, en la Península Ibérica se halla Sosimilos en CIL II 3295, Cástulo (Jaén), y Sosumilus EE.9.358, en Denia (Alicante).

El segundo bronce de Botorrita, denominado Tabula Contrebiensis, es una tabula de bronce de 43,8 x 20,8 x 0,5 cm., escrita en latín. En él se juzga y dirime un pleito sobre unas canalizaciones de agua que involucra a tres ciudades:

a. La de los salluienses $=$ saltuie $/ *$ Salluie/ Zaragoza.

b. La de los sosinestanos, de localización desconocida.

c. La de los allauonenses = alaun/Alagón (Z).

Contrebia Belaisca, ciudad en cuyo senado (Senatus Contrebiensis) se celebra el juicio y cuyos senadores son los jueces con potestad para dirimirlo, no está involucrada en el pleito. El personaje que sanciona el procedimiento judicial es Cayo Valerio Flaco, hijo de Cayo, que había sido el último triunfador sobre los celtíberos.

Se conoce incluso en qué fecha se tomó la decisión final: eidibus maieis L. Cornelio Cn. Octauio consulibus, esto es el 15 de mayo del 87 a.e. En el documento aparecen varias fórmulas onomásticas:

a. La del defensor de la causa de los saluienses
(-) assius
(-) eiharf
salluiensis

b. La del defensor de la causa de los alavonenses
Turibas
Teitabas $f$
(allauo)n(en)ș(is)

Tanto en el Bronce de Ascoli, como en el segundo de Botorrita, la fórmula onomástica ibérica es la esperada: idiónimo más patrónimo. No así las que aparecen en el tercer bronce, que son típicamente celtibéricas: idiónimo más genónimo o idiónimo más genónimo más patrónimo.

El patrónimo del defensor saluiense aparece con una h, letra y supuesta aspiración (;fricativa glotal sorda!), a la que casi automáticamente se le concede marchamo vascónico. Y en efecto, ese rasgo aparece en esa onomástica, como habrá ocasión de comprobar y de lo que se volverá a hablar. De ahí que al padre del saluiense (-)assio se le otorgue esa «nacionalidad», lo mismo que a Chadarque aparece en el Bronce de Ascoli. No hay, sin embargo, nada allí ni aquí que diga que son vascones. Cacususin hijo de Jádar es bagarense, ciudad que no se ha sabido localizar; pero es que -asio hijo de -eihar es saluiense, ciudad ibera; Turibas hijo de Teitabas, con clara antroponimia ibérica es alavonense, ciudad vascona según Ptolomeo (2.6.66), con acuñaciones numismáticas de tipo ibérico, y cuyo topónimo parece indoeuropeo.

Pero no es este el único caso de mezcla antroponímica, etnonímica y toponímica. Paradigmático es el de la ciudad de Segia, ciudad que emitió 
moneda [A.43] y que se localiza en la actual Ejea de los Caballeros en la provincia de Zaragoza. Etimológicamente zekia podría tener un étimo indoeuropeo * seg $^{h-}$ 'victoria' (cf. Segovia, por ejemplo), corriente en la toponimia celta. De nuevo Ptolomeo $(2,6,67)$ la cita entre las ciudades vasconas y los caballeros segienses del Bronce de Ascoli son de nombre indudablemente ibérico, como acaba de verse.

En la antroponimia de los magistrados contrebienses, no hay ningún problema en la adaptación, que en algún caso supone una operación no sólo fonética, sino también morfológica:

$\begin{array}{llll}\text { Lubbus } & \text { Urdinocum } & \text { Letondonis f. } & \text { Praetor } \\ \text { Lesso } & \text { Siriscum } & \text { Lubbif. } & \text { (Ma)gistratus } \\ \text { Babpus } & \text { Bolgondiscum } & \text { Ablonis f. } & \text { Magistratus } \\ \text { Segilus } & \text { Annicum } & \text { Lubbif. } & \text { Magistratus } \\ \text { (-)atu } & \text { (-)ulouicum } & \text { Uxentif. } & \text { Magistratus } \\ \text { Ablo } & \text { Tindilicum } & \text { Lubbif. } & \text { Magistratus }\end{array}$

- Lubbus: Está testimoniado en la documentación celtibérica en [K.1.1, B1], como lubos kounesikum melmunos. El correspondiente genitivo de lubos en celtibérico es *lubo, pero aparece $L u b$ $b i$ (x2), el genitivo latino de Lubbus.

- Letondonis: genitivo de Letondo, en documentación celtibérica letontu, letontunos, cf. [K.16.1] tirtanos abulokum letontunos ke belikios. A un genitivo celtibérico en $-o s<*_{-}$os le corresponde uno latino en $-i s<*-\check{s}$.

- Lesso: No está testimoniado el nominativo, pero sí el genitivo en [K.1.1, B2] melmu barauzanko lesunos y B6 tirtanos statulikum lesunos. El N. celtibérico es *lesu.

- El caso de Ablo, Ablonis es ciertamente complicado. A Ablo parece corresponderle en la documentación celtibérica abulu, cf. [K.1.1]: [A11] abulu ubokum, [B4] abulu louzokum useizunos, [B8] abulu aiankum tauro. La -u- de la secuencia -bu- es, por lo tanto, muda. El genitivo celtibérico de este nominativo es abulos [B2] letontu litokum abulos, [B4] aiu berkantikum abulos, [B4] tirtu aiankum abulos, [B8] letontu letikum abulos, [B9] letontu esokum abulos. La mejor explicación es partir de *abul-n-os, con una- $u$ - de difícil explicación. Si la correspondencia de Ablo, -onis es abulu, abulos, la operación que ha tenido lugar aquí es ciertamente de calado morfológico, pues frente a la generalización del grado alargado

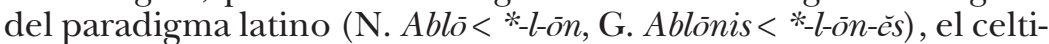
bérico parece presentar uno con grado alargado en el nominativo $\left(-\mathbf{l u}<*_{-l-\bar{o} n)}\right.$, cero en el genitivo $\left(-\operatorname{los}<*_{-}-l-n-\bar{o} s\right)$.

- Tanto Babpus que parece se corresponde con [K.1.3, III 56] babos kentiskue uiriaskum, y Segilus que se lee en [K.1.3, I 7] sekilos toutinikum me + y [III 23] sekilos mailikum, son temas en - $o$ y no presentan mayor problema que el del cambio de timbre. 
- Los genitivos plurales de los genónimos aparecen en -um, forma celtibérica, pero posibilidad morfológica presente en latín.

En definitiva, en el siglo II y sobre todo en el I a.e., los hablantes y escritores de lenguas indoeuropeas, como lo era un celtiberófono o un latinoparlante, no encontraban excesivos problemas en reconocer y adaptar los patrones morfológicos de la antroponimia del otro. En cambio, no sucedía lo mismo cuando tenían que fijar por escrito la antroponimia ibérica, que parece ser adoptada en el correspondiente «caso de la nominación» ibérica y utilizado tal cual independientemente de su función sintáctica. Los esfuerzos para adaptar este material a la morfología latina vienen de la mano de los iberos que van a ir latinizándose, en todos los aspectos, tal y como puede rastrearse en la epigrafía escrita por ellos, pero en latín. Hay poco material de época republicana y un poco más de la imperial, pero el proceso de adaptación desapareció con la completa latinización cultural de esa población.

De momento no se han encontrado referencias antroponímicas celtibéricas en documentación y territorio ibéricos. El único testimonio de antroponimia celtibérica en un documento ibérico que se conoce en la actualidad se encontró en zona celtibérica. Es la cartela del mosaico de Caminreal, provincia de Teruel. En ella aparece escrita la palabra likine que corresponde a un antropónimo celtibérico likinos, testimoniado en el tercer gran bronce varias veces.

Esta aparente impermeabilidad de las zona celtibérica e ibérica en la margen derecha del valle medio del Ebro contrasta y mucho con lo que sucede en la región narbonense en Francia y lo que es la actual provincia de Gerona. Allí existen claras huellas de antroponimia celta, en este caso gala, compitiendo con la ibérica, sobre todo en cerámica, aunque también la hay en plomos. Estos textos se datan entre los siglos III y II a.e. La aparición de esta antroponimia se achaca al advenimiento de los Volcae Tectosages, pueblo celta, en Toulouse y zonas del sudeste de Francia, que se superpuso a la población de la zona, que había sido fuertemente iberizada en los siglos vi y v a.e. (Gorrochategui 2002, pp. 79-80).

En esta documentación se halla el plomo de Ensérune, en el que aparece el antropónimo katubare-ka, que se corresponde a un Catumarus. Aquí puede observarse otra vez la adaptación en -e. De nuevo se da un caso de adopción de antropónimos de temas en -o de una lengua indoeuropea bajo la forma - $e$ en una lengua no-indoeuropea, que hay que añadir a lo detectado entre el latín y el etrusco; el latín y el neopúnico; y seguramente se podría extender a lo que pasa entre el latín y el ibérico a juzgar por lo que sucede con los temas en -yo, que parecen seguir la misma regla que entre el galo e ibérico y celtibérico e ibérico. Y parece que también se da este tipo de transferencia entre el copto y el griego. La aparición en distintos ámbitos y en distintas cronologías parece apoyar la idea de que efectivamente las lenguas adoptantes tomaron estos antropónimos a partir del correspondiente vocativo, caso en 
absoluto extraño para la antroponimia (cf. J. A. Correa 1993, p. 103 para la propuesta entre galo e ibérico y Adams 2004 en los correspondientes capítulos para las otras referencias).

\section{MARGEN IZQUIERDA}

Ya se ha dicho que la margen izquierda del Valle Medio del Ebro, desde Logroño al Cinca, presenta un panorama epigráfico paleohispánico desolador si se compara con la margen derecha. En cuanto uno se aleja de la costa catalana, el material ibérico se encuentra al sur de la provincia de Lérida, en el bajo Segre. Como ya se ha indicado, es entre La Noguera-Ribagorzana y el Cinca donde se hallan los documentos que parecen actuar de mojones paleo-epigráficos ibéricos: la estela encontrada en el yacimiento de El Pilaret de Santa Quiteria, Fraga (HU) [D.10.1], actualmente perdida, y el monumento de La Vispesa, en Binéfar (HU) [D.12.1]. A partir de aquí y hasta la frontera occidental de Navarra se abre un territorio de difícil descripción y adscripción lingüística. Es aquí donde lo celta, no ya precisamente lo celtibérico, lo ibérico y lo vascónico se tocan, pero de una manera que no se puede determinar con exactitud de momento. Y no se puede hacer porque el material epigráfico-lingüístico que existe es poco y difícilmente interpretable.

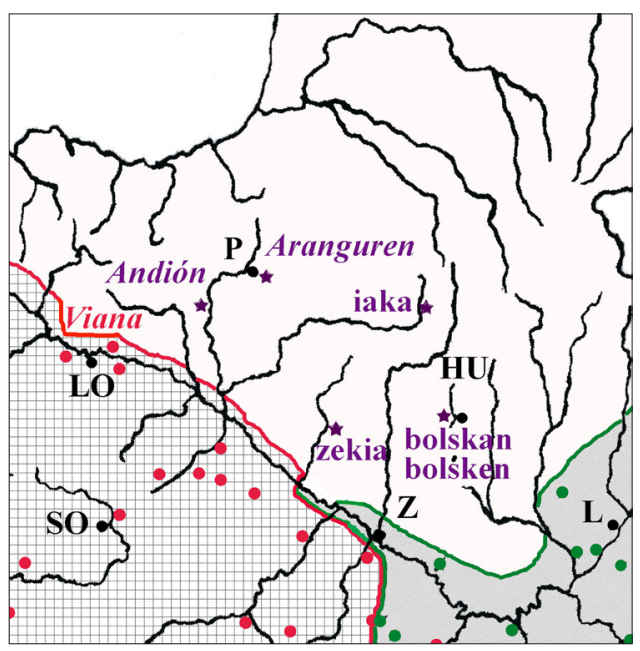

Mapa 3: Hallazgos, indicados con una estrella, en la margen izquierda del Valle Medio del Ebro. En cursiva se indican localidades actuales; en minúsculas se señalan los nombres que aparecen en las leyendas monetales.

El término «vascón», etnónimo metido a glotónimo, está utilizado en el presente trabajo para referirnos a una lengua paleohispánica: 
a. Que fue hablada por gentes cuyo hábitat se extendía por la margen izquierda del Valle Medio del Ebro, es decir, por las actuales provincias de Navarra (incluido el corredor del Bidasoa en Guipúzcoa), norte de la de Zaragoza y mitad occidental de la de Huesca.

b. Que con seguridad está testimoniada indirectamente. Así se hallan antropónimos pertenecientes a esa lengua en epigrafía latina: Ummesahar, Narhungesi, Abisunhari (Lerga, NA); Edsuri (Urbiola, NA); Abisunsonis (Olza, NA); Serhuhoris (Valpalmas, Z); Dusanharis (Sofuentes, Z); Nar[u]/[ng]eni (Sofuentes, Z). Se encuentran también teónimos vascones en epigrafía latina: Errensae (Larraga, NA); Larrahi (Mendigorría, NA); Losae (Lerate, NA, x2); [L] osae (Cirauqui, NA); Loxae (Arguiñáriz, NA); Selatse (Barbarin, NA, x2); Itsacurrinne (Olza, NA).

En estos textos de época imperial se hallan unas referencias antroponímicas y teonímicas que se relacionan en algunos casos sin dificultad con la antroponimia y teonimia que se encuentra en una serie de inscripciones funerarias y votivas de la región aquitana, que a su vez, como ya dejó bien claro J. Gorrochategui (1984), presentan unas concomitancias con la onomástica medieval vasco-navarra que no dejan lugar a dudas de que se trata, salvando las diferencias diacrónicas y diatópicas, de la «misma» lengua. Es decir, que en el siglo I anterior y posterior de nuestra era se puede pensar en un continuum lingüístico aquitano-vascón a ambos lados de los Pirineos.

c. Cuyo grado de continuidad con la actual lengua vasca en sus distintas variedades está por determinar. Desde luego, los datos que se conocen, tal y como pueden interpretarse (v. en este sentido Villar 2005), no son precisamente favorables a la tesis de una descendencia directa de ese vascón paleohispánico. Y no lo son porque el material antroponímico, teonímico y toponímico que puede extraerse de la epigrafía latina y las fuentes clásicas etimologizable desde el vasco o que pueda ser considerado paleovasco es muy escaso. Se plantea entonces la pregunta: ¿a qué se debe esa escasez? ¿Son restos de un estrato antiguo más rico al que se superpone otro u otros? o ¿es que ese sustrato paleovasco no era tan denso como se supone? Esta última es la cuestión clave por dos razones. La primera, porque si hubiese habido tal densidad de población hablante de paleovasco se esperaría una mayor densidad de toponimia de ese tipo. La segunda es porque no se ha interpretado correctamente el término vascón y además se ha abusado de él como glotónimo. Puede resumirse el problema en una pregunta: ¿a qué se refieren exactamente las fuentes clásicas con el término 
uascones: a los hablantes de una determinada lengua, o tiene otro carácter?

No es necesario recordar que el material lingüístico que se conoce de los pueblos nombrados por las fuentes clásicas y que ocupaban lo que es actualmente el País Vasco (y zonas aledañas) apunta a un origen indoeuropeo y celta. Estos pueblos eran: los autrigones, en la zona del suroeste y noroccidental de Álava, así como en los territorios a la izquierda del Nervión en Vizcaya; los caristios, en el resto de la provincia vizcaína y alavesa y parte de Guipúzcoa; y los várdulos, en el resto de Guipúzcoa, excepto el corredor del Bidasoa (v. por ejemplo Gorrochategui 1995).

En cuanto al material paleohispánico escrito que se ha encontrado en la margen izquierda del Valle Medio del Ebro y cuya localización se conoce sin ningún género de dudas es el conjunto de las téseras de hospitalidad de La Custodia, Viana (NA); el bronce de Aranguren (NA); el mosaico de Andelo (NA); y tres cecas de las denominadas vascónicas, en Ejea de los Caballeros (Z), Jaca (HU) y Huesca.

a) Las téseras de hospitalidad de La Custodia, Viana (NA): Entre finales de los ochenta y comienzo de los noventa, se dieron a conocer cuatro téseras procedentes de ese yacimiento.

La tésera de hospitalidad es el documento estrella del mundo celtibérico. Se cuenta con alrededor de una treintena, incluyendo estas cuatro. Se trata de un documento portátil, que recoge un pacto cuya naturaleza todavía no ha sido bien determinada. Las dos teorías que mejor aceptación han tenido son la de que están reflejando un pacto de hospitalidad de carácter indígena o bien que se trata de una concesión de ciudadanía. Son de pequeño tamaño y pueden tener carácter figurativo (zoomorfas y antropomorfas) o geométrico. Su transcripción según los Monumenta Linguarum Hispanicarum es:

[K.18.1] berkuakum : sakas

[K.18.2] [-]+iko : loukio : kete[-] / [-]ko

[K.18.3] kubokariam : ueniakum / iteulases : buntunes

[K.18.4] sakarokas

Tras realizar la autopsia (31.05.07) de todas las piezas, quizá se pueda dar una lectura alternativa de [K.18.3]:

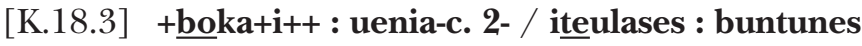

Estos documentos se estudian dentro del material celtibérico y desde el punto de vista del tipo documental pertenecen a él. Geográficamente se hallan en zona berona. El poco material que se posee de los berones no permite afirmar con rotundidad que su lengua fuese una variante lingüística diferente al celtibérico. Aunque no hay que olvidar que son unos documentos portátiles y por lo tanto el emisor podría no ser berón. 
b) [K.25.1] El Bronce de Araguren (NA).

Se trata de un fragmento de bronce muy deteriorado. La tipología documental, placa de bronce, y la forma de grabación, por punteado, apuntan a hábitos celtibéricos. Las cadencias que se leen y la forma de algún alógrafo van en dirección a lo ibérico. Su localización tan occidental puede deberse a un traslado cuyas causas desconocemos. Las propuestas de lectura son:

- Untermann 1997:

Cara A: ]rn+[ / +be[]kur.be[ / turs.ki[ / beltine[ / -]rska[ / ]+n[ Cara B: ++[]s.ta / ]nez / ]kane / ]kusor[- / ]++[

- Beltrán y Velaza 1993:

Cara A: - / [-]+boŕkaŕ · be [-] / [-]tứś • ki [-] / [-]beltine[-] / [-]+ŕśka+[-] / [-] uacat $[-] /$ -

Cara B: - / [-]+be+[-] / [-] titu+śs t ta[-] / [-]nes+ti++[-] / $[-]+k a n e+[-] /[-]$ kuśó́ $[-] /[-]$ ś+[-] / -

c) El Mosaico de Andelo.

En 1990 en la antigua Andelo, cuyos restos arqueológicos se hallan junto a la actual ermita de Nuestra Señora de Andión, en Muruzábal de Andión, a 4,5 km. al sur de Mendigorría, en Navarra, se encontró un mosaico de opus signinum (tipo de mosaico consistente en la incrustación de teselas de diferentes colores y tamaños sobre un pavimento liso de polvo, ladrillo y teja). Este mosaico adorna el patio de una villa de tipo romano, datada a mediados del siglo II a.e. y presenta una inscripción, dentro de una cartela de 244 por $19 \mathrm{~cm}$., en signario ibérico que reza como sigue:

\section{likine : abuloŕaune : ekien : bilbiliaŕs}

El estudio lingüístico de esta inscripción ha estado marcado por las indudables concomitancias, no sólo lingüísticas, sino también de factura y de tipo, con otra inscripción, que ya ha sido nombrada, encontrada pocos años antes en las excavaciones de La Caridad, Caminreal (Teruel). Este poblado corresponde a una fundación ex nouo de mitades del siglo II a.e. y fue destruida violentamente c. 70 a.e., durante las guerras sertorianas. Nos hallamos ahora en territorio lingüístico plenamente celtibérico. Sin embargo, toda la ciudad y la construcción en la que se encontró el mosaico, una mansión de unos $900 \mathrm{~m}^{2}$ organizados alrededor de un patio cental, es de factura romana. En esa misma casa se han encontrado dos morteros: uno con una inscripción latina: [Fl Atili / $L$ (uci) $S$ (eruus)] y otro con una inscripción ibérica: [bilake aiunatin / en abiner]; dos inscripciones sobre instrumentum domesticum: en una copa se lee kambarokum y en un oinochoe se lee beskuauzuetikubos, en celtibérico; una tésera de hospitalidad en la que se lee, también en celtibérico, 
lazuro : kosokum / tarmestutez : kar (Beltrán 1995). Y por fin, el mosaico con el siguiente texto, dentro de una cartela de 246 por $19 \mathrm{cms}$.:

likinete : ekiar : usekeŕteku

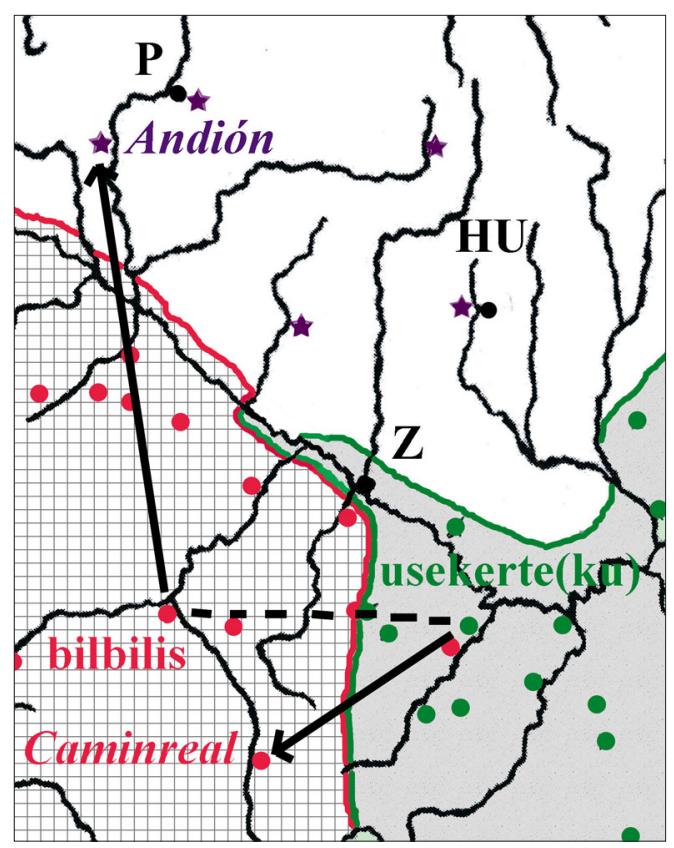

Mapa 4: Localidades implicadas en las cartelas musivarias de Andelo y La Caridad.

Esto no parece celtibérico en ninguno de los dos casos. Sin embargo, tanto likine como abulo son dos nombres bien testimoniados en la antroponimia celtibérica y en concreto el segundo de ellos es propiamente celtibérico. Además, bilbili-, bilbiliz/bilbili [A.73], es la Bilbilis celtibérica, actual Calatayud (Zaragoza).

Por otro lado, usekerte [A.26] es el nombre ibérico de la ciudad con nombre latino Osicerda, de difícil localización, pero que parece seguro poder buscarse por el Bajo Aragón, en concreto en La Puebla de Híjar (Beltrán 1996). La aparición de -te, ekiar, y -ku en la documentación ibérica apuntan a que al menos en el caso de La Caridad es un mensaje escrito en lengua ibérica.

Del resto de los elementos no onomásticos, sin duda la pareja ekiar / ekien es la que más ha dado que hablar. ekien es un unicum, no así ekiar. El análisis de la documentación ibérica en que aparece ekiar y, aunque con alguna dificultad, los paralelos latinos y griegos, permite pensar con poco margen de error que es una palabra que pertenece al campo semántico de «hacer». 
La relación con «hacer» se llevó a cabo muy pronto desde otra perspectiva: la vasco-iberista. El vasco-iberismo es esa corriente de estudios que considera que entre la lengua vasca y la ibérica existe algún tipo de parentesco genético. La relación se estableció por el aparente parecido que existe entre las secuencias ekiar/ekien con el verbo egin. Hay que subrayar «aparente parecido» pues lo primero que no se conoce es el contenido fónico de esas secuencias de transcripción. Es decir ekiar/ ekien pueden corresponder a [egiar], [egien], pero también a [ekiar, ekien]. En vasco existe el verbo egin 'hacer', 'dar', 'apostar', 'suponer' y ekin 'ocuparse' 'inculcar, insistir' 'emprender, comenzar', 'atacar'.

En los últimos tiempos, J. Velaza (en prensa), desde presupuestos que nada tienen que ver con el vasco-iberismo ha dejado abierta la posibilidad de que la cartela de Andelo sea el texto escrito en vasco más antiguo. Mientras que no ve ningún problema en interpretar el texto turolense likinete : ekiar : usekérteku como ibérico, en el texto navarro likine : abuloŕaune : ekien : bilbiliaŕs encuentra obstáculos tanto lingüísticos como artísticos. Como indica con toda razón, la secuencia bu es un serio impedimento para su interpretación desde el ibérico, pues tanto el silabograma como la secuencia fónica que representa son insólitos en esa lengua. Por otro lado, si se admite que estamos ante la firma de un artesano, no ve del todo claro que el dueño de una casa (que supone era vascón, pues está en territorio vascón) permitiese una firma en una lengua extraña.

La forma que podría interpretarse desde el vasco es ekien, que debería leerse [egien] y podría ser considerada como «la forma de pretérito sintético del verbo egin 'hacer' egien sin la marca z-de pretérito generalizada en los dialectos centrales y orientales, zegien, aunque no así en las occidentales» (Gorrochategui, 2006, pp. 121-122). El autor de este análisis morfológico, J. Gorrochategui, no termina de estar convencido de su propuesta, pues entre otras cosas no se aprecia una marca de ergativo, a no ser que se pudiese demostrar que en esos momentos ese paleo-vasco carecía de ella (Gorrochategui ibid. n.22).

Además de este pequeño inconveniente, los obstáculos para entender esto como ibérico no son insalvables. En efecto, la secuencia bu es insólita en ibérico, pero no hay que olvidar que está reproduciendo un antropónimo celtibérico. En cuanto a que sea la firma del artista en una lengua extraña al dueño de la casa, habría que determinar en primer lugar que el dueño era vascón; y en segundo lugar en Caminreal todo parece apuntar que los habitantes de la casa eran celtiberófonos y en cambio la firma está en ibérico. Además, en la misma Muruzábal de Andión se encontró una lápida latina (CIL II 2967) donde se lee Calpur/niae Ur/chatetelli / L Aemilius / Seranus / matri. El antropónimo Urchatetelli puede ser analizado desde el ibérico sin problemas: cf. CIL II 1087 (Alcalá del Río, Sevilla) Urchail · Atitta $\cdot$ f(ilius) / Chilasurgun / portas 
- fornic(es) / aedificand(os) / curauit · de $\cdot s(u a) \cdot p($ ecunia $)$, Alcalá del Río, Sevilla para la primera parte; y Azaila, TE, [E.1.375 y 376] biu tetel para la segunda. La aparición de la «aspiración» en Urchatetelli (además de la geminación o fortalecimiento de la líquida final) son argumentos a juicio de Gorrochategui 2006, p. 133 que apuntan a una adaptación de un nombre ibérico a hábitos vascónicos. Resulta bastante sospechoso, sin embargo, que Urchail también aparezca con «aspiración», a no ser que se achaque a hábitos púnicos...

d) Leyendas monetales de las cecas de estilo vascón.

La parte occidental de la provincia de Huesca, la colindante a ella de la provincia de Zaragoza y la provincia de Navarra es el territorio de las denominadas cecas de tipo de «cabeza vascona» o simplemente de «estilo vascón». Esta denominación se debe a una característica iconográfica propia: la representación de una cabeza de hombre, con un perfil salido singular y unos rizos encima de la frente que terminan en un gancho pronunciado (Untermann 1975). Tienen también unas características metrológicas homogéneas (Villaronga 1994), así como unas peculiaridades paleo-epigráficas (Beltrán 2001). Las únicas que están bien localizadas son las indicadas de iaka en Jaca (HU), zekia en Ejea de los Caballeros y la de bolskan/bolśken en Huesca.

Las dificultades en la clasificación lingüística del material documentado en la margen izquierda del Valle Medio del Ebro alcanzan con este grupo epigráfico su máxima expresión.

Desde el punto de vista lingüístico pueden clasificarse en un primer conjunto en el que las leyendas parecen ajustarse morfológicamente a los patrones celtibéricos (e indoeuropeos):

Posibles nominativos singular de temas en $-a$ : benkota [A.38, A.39] (localización desconocida). iaka [A.41] (Jaca, Huesca).

zekia [A.43] (Ejea de los Caballeros, Zaragoza).

Posibles ablativos del singular:

barskunez [A.38-3] (loc. desc. NA), de tema en nasal. baskunez [A.38-1] (loc. desc. NA), de tema en nasal. ontikez [A.42] (loc. desc.), de tema en velar.

Y uno segundo que no se dejan reducir a ellos:

unambaate [A.46] (hacia Treviño).

bentia, bentian [A.39] (loc. desc. NA).

bolskan/bolśken [A.40] (Osca, Huesca).

arzakoz, arzakozon [A.36] (loc. desc.).

arzaoz [A.37] (loc. desc. ¿Aragón?).

tirzoz [A.45] (loc. desc.).

zezarz [A.44] (loc. desc. ¿Sesa, HU?).

olkairun [A.60] (loc. desc.). 
La terminación en - $n$, que aparece en varias cecas del segundo grupo, ha sido utilizada y sigue siéndolo como una marca que apunta a la vasconicidad del topónimo (y de los hablantes de la localidad).

Así sucede con [A.39] bentia, bentian. De localización desconocida, se propone la provincia de Navarra. De Hoz 1995, pp. 274-275, extrajo aquí un posible sufijo -n, que recuerda al sufijo locativo vasco de nombres propios del tipo Lesakan, Baigorrin, Eibaren, y que en una moneda, quizá podría significar algo así como «acuñado en». La deducción la llevó a cabo a partir de la relación entre:

bentian - bentia
bolskan osca $<*(b)$ olska

que a su vez, considerando que el latino Osca puede ser el resultado procedente de $*$ olska, contaría con un prefijo $b$-, cuyo valor y significado se desconocen.

Ahora bien, el hecho de que aparezca un morfema de una lengua, no quiere decir que el lexema pertenezca a la misma. Esta leyenda podría ser un buen ejemplo de ella. A. Marques de Faria 2000, p. 136, considera que hay que leerla como mendian y la explica, obviamente como vasca. Una simple confusión $m / b$ y el sufijo - $n$ dejan clara, a su juicio, la vasquicidad lingüística del topónimo. Sin embargo, parece haber serias dudas sobre la existencia en esta época del artículo en paleo-vasco.

Además, hay otras posibilidades etimológicas, como indica Villar 2002, quien propone considerar esta leyenda dentro de la serie toponímica pent-, pint- procedente de *penk $k^{w} t i a$, basada en el ordinal *penk $k^{w}$-tó- 'quinto', cuyo cardinal era *penk $k^{w} e$ 'cinco' y que, debido al tratamiento de la labial inicial difícilmente puede considerarse celta. Sería una ciudad homónima a la población vaccea que Ptolomeo 2,

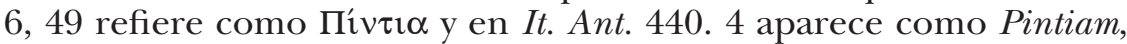
localizada en la provincia de Valladolid. La forma Pintia reflejaría un paso -en->-in-. Queda sin resolver el problema de la - $n$ final, que tiene muy mal acomodo si consideramos la leyenda en una lengua indoeuropea.

En el asunto del pretendido sufijo $-n$ también estaba implicada la leyenda [A.40]. Ésta se ha leído tradicionalmente como bolskan y debido al lugar de los hallazgos se ha identificado siempre con Osca (Huesca), intentando establecer una continuidad fonética entre ambas. Además, como se ha visto, se utilizó junto con bentia, bentian, para segmentar $-n$.

Rodríguez Ramos 2001-2002 propuso acertadamente releer la leyenda como bolśken y no bolskan, con lo que una palabra de morfología vascónica se convierte en una con morfología ibérica. En efecto, la segmentación bol-śken permite extraer un sufijo que aparece varias veces en leyendas monetales ibéricas: untikesken [A.6], auśesken [A.7], laieśken [A.13], iltiŕkesken [A.19], otobeśken [A.23], seteisken [A.25], 
ikalesken [A.95], urkesken [A.96]. De Hoz 2002, p. 162, ha analizado el sufijo -(e)sken como la combinación de tres elementos: -es indicador de origen; - $k e$ - formador de étnico o pluralizador; y -en indicación de pertenencia. Así es que se podrían interpretar las leyendas como «(moneda) de [pertenencia] -los originarios- de [origen] Undica» (Ampurias, Gerona), de manera abreviada, «de los de Ausa» (Vich, Barcelona), «de los de Laie» (Barcelona), «de los de Ilerda», «de los de Otobesa» (¿Mequinenza?, Zaragoza), «de los de Sedeis» (prov. de Zaragoza), etcétera.

Teniendo en cuenta que la latinización de auśesken es ausetanorum y la de laieśken laietanorum, parece lógico pensar que la de bolśken sea boletanorum. En CIL II 5845 se lee L(ucio) Val(erio) Gal(eria) / Materna / Boletano / M(arcus) Cor(nelius) Pompe/ianus amico opti/[.]o obmerita / -, donde se hace referencia a un boletanus, Lucio Valerio de la tribu Galeria, que vuelve a aparecer en CIL II 5843, esta vez con el etnónimo de manera abreviada. Se desconoce dónde habitaban los boletani, pero a finales del xıx, a partir de ciertos documentos medievales, se creó el nombre de Boletum, que fue identificándose con la localidad oscense de Boltaña en el Pirineo Aragonés. Cercana a la capital altoaragonesa se encuentra la localidad de Bolea. ¿Casualidad?

Quizá sea el momento de replantearse esa identificación, de pensar que el nombre indígena de Huesca comenzaba por bol-, que no existía ninguna relación etimológica entre él y la denominación latina Osca y que estamos ante un caso más de duplicidad toponímica, que no tiene por qué referirse ni siquiera a la misma localidad exactamente. Nadie parece rasgarse las vestiduras ante pares como arse / Saguntum, kese / Tarraco y untikesken / Emporion.

Aviso a navegantes de las procelosas aguas etimológicas: últimamente se está colando un fantasma toponímico como intermedio entre * bolskan y Huesca, que se ha oído en alguna reunión científica: Walqa. Es el nombre del parque tecnológico que existe a la entrada de Huesca, pero es una invención moderna. No aparece en las fuentes árabes.

También termina en - $n$ la leyenda [A.60] olkairun, ceca de localización desconocida. Quizá la primera parte de esta palabra olka- proceda de un *polkā 'campo' (cf. español huelga 'terreno de cultivo, especialmente fértil'), cuyo tratamiento fonético se compadece muy bien con el celta. Queda en la oscuridad el segundo segmento -irun, pues la propuesta de A. Tovar de hacerla provenir del vasco iri 'ciudad' es difícilmente sostenible, según demostró Gorrochategui 1995, p. 221: la palabra iri debe proceder de una anterior con una líquida, que sufre rotacismo en una época posterior a la de la leyenda monetal. Y, por cierto, esa protoforma *ili difícilmente puede equipararse con el famoso segmento ibérico ilti-, iltu-, etc., con seguridad 'ciudad', pues apunta a una líquida diferente.

Este es un buen ejemplo para denunciar un error bastante habitual 
entre los practicantes del vasco-iberismo desaforado. Las comparaciones que suelen establecer entre secuencias ibéricas y vascas son llevadas a cabo sin caer en la cuenta o sin querer caer en la cuenta de que están comparando material con una diferencia cronológica en el mejor de los casos de unos quince siglos. Sencillamente no tienen en consideración la prehistoria del vasco y eso es un grave error metodológico.

La única leyenda de este grupo que permite un análisis verosímil desde el indoeuropeo a pesar de terminar en -n es arzakozon [A.36]. Villar 2000, pp. 398-399, ha propuesto interpretarla como un genitivo plural de una forma adjetival. Conformado con el sufijo - $k 0_{-}$, presentaría la terminación pronominal *-sōm con el mantenimiento de la -o-y la transformación de $-m$ en $-n$, fenómeno que se detecta en diferentes lenguas indoeuropeas. Queda por determinar la relación con arzakoz.

Los problemas con estas leyendas monetales no se acaban con los expuestos (un acercamiento lingüístico general a todo el conjunto numismático puede verse en Jordán 2004, pp. 203-209). De todas las formas, el reanálisis de [A.40] como bolśken y la homogeneidad de la antroponimia ibérica de los segienses del Bronce de Ascoli apuntan a que la frontera lingüística ibérica podría desplazarse por el oeste, cuando menos, hasta el río Arba (provincia de Zaragoza) y por el norte hasta el pre-pirineo zaragozano y oscense (Sierra de Salinas, Sierra de Loarre y Sierra de Guara).

Pero más allá de preguntas concretas sobre tal y cual fonema, morfema y lexema; sobre las posibilidades de clasificación genética de todo el material aquí tratado; y sobre fronteras lingüísticas, queda en el aire una inquietante incógnita: ¿por qué existe esa diferencia documental entre una margen y la otra del Valle Medio del Ebro?

\section{REFERENCIAS BIBLIOGRÁFICAS}

Adams, J. N. (2004): Bilingualism and the Latin language, Cambridge, Cambridge University Press.

Beltrán Lloris, F. (1993): «La epigrafía como índice de aculturación en el valle medio del Ebro (s. II a.e. - II d.e.)», en Untermann, J. y Villar, F. (eds.), Lengua y cultura en la Hispania prerromana. Actas del V Coloquio sobre lenguas y culturas prerromanas de la Península Ibérica (Colonia, 25-28 de Noviembre de 1989), Salamanca, pp. 236-272.

- (1995): «La escritura en la frontera. Inscripciones y cultura epigráfica en el Valle Medio del Ebro», en Beltrán, F. (ed.), Roma y el nacimiento de la cultura epigráfica en occidente, Zaragoza, pp. 169-195.

— (1996): «Una liberalidad en la Puebla de Híjar (Teruel) y la localización del Municipium Osicerda», AEspa 69, pp. 287-294.

- (2001): «Hacia un replanteamiento del mapa cultural y étnico del norte de Aragón», en Villar, F. y Fernández Álvarez, Mํㅗㄹ P. (eds.), Religión, lengua y cultura prerromanas de Hispania. Actas del VIII Coloquio sobre lenguas y culturas 
prerromanas de la Península Ibérica (Salamanca, 11-15 de mayo de 1999), Salamanca, pp. 61-81.

- (2004): «Las inscripciones ibéricas en el contexto de la epigrafía republicana», E.L.E.A. 5, pp. 51-74.

- (2006): «El Valle Medio del Ebro durante el período republicano: de limes a conuentus», en Cruz Andreotti, G., Le Roux, P., y Moret, P. (eds.), La invención de una geografía de la Península Ibérica. I. La época republicana, Málaga, pp. 217-240.

— Hoz, J. De y Untermann, J. (1996): El tercer bronce de Botorrita (Contrebia Belaisca), Zaragoza.

- y Ortiz, E. (2003): «Burdo Medugeno munus dedit. Sobre una cotícula inscrita del Museo de Zaragoza», Palaeohispanica 2, pp. 295-325.

—y VelazA, J. (1993): «Una nueva inscripción ibérica sobre bronce (Aranguren, Navarra)», en Adiego, I. J., Siles, J. y Velaza, J. (eds.), Studia Palaeohispanica et Indogermanica J. Untermann ab amicis hispanicis oblata, Barcelona, pp. 89-99.

Correa, J. A. (1993): «Antropónimos galos y ligures en inscripciones ibéricas», en Adiego, I. J., Siles, J. y Velaza, J. (eds.), Studia Palaeohispanica et Indogermanica J. Untermann ab amicis hispanicis oblata, Barcelona, pp. 101-116.

FatÁs, G. (1980): Contrebia Belaisca (Botorrita. Zaragoza). II. Tabula Contrebiensis, Zaragoza.

— (1998): «El Ebro medio, trifinio paleohispánico», en Rodríguez Neila, J. F. y Navarro Santana, F. J. (eds.), Los pueblos prerromanos del Norte de Hispania. Una transición cultural como debate histórico, Pamplona, pp. 29-50.

García-Bellido, Ma P. y Blázquez, C. (2001): Diccionario de cecas y pueblos hispánicos, 2 Vols., Madrid.

Gorrochategui, J. (1984): Estudio sobre la onomástica indígena de Aquitania, Bilbao.

- (1993a): «La onomástica aquitana y su relación con la ibérica», en Untermann, J. y Villar, F. (eds.), Lengua y cultura en la Hispania prerromana. Actas del $V$ Coloquio sobre lenguas y culturas prerromanas de la Península Ibérica (Colonia, 25-28 de Noviembre de 1989), Salamanca, pp. 609-634.

- (1993b): «Onomástica indígena de Aquitania: adiciones y correcciones I (OIA Add. I)», en Heidermanns, F., Rix, H. y Seebolds, E. (eds.), Sprachen und Schriften des antiken Mittermeerraums. Fs. für Jürgen Untermann, Innsbruck, pp. 145-155.

— (1995): «Los Pirineos entre la Galia e Hispania: las lenguas», Veleia 12, pp. 181-234.

— (2002): «Las lenguas de los Pirineos en la antigüedad», Els substrats de la llengua catalana: una visió actual, Treballs de la Societat Catalana de Llengua i Literatura I, pp. 75-101.

- (2006): «Onomástica vascónica y aquitana: elementos para el conocimiento de la historia antigua en Navarra», en Andreu Pintado, J. (ed.), Navarra en la Antigüedad. Propuesta de Actualización, Pamplona, pp. 111-134.

Hadas-Lebel, J. (2004): Le bilinguisme étrusco-latin. Contribution à l'étude de la romanisation de l'Étrurie, Louvain-París-Dudley, MA.

Hoz, J. de (1995): «El poblamiento antiguo de los Pirineos desde el punto de vista lingüístico», Muntaynes i població. El passat dels Pirineus des d'una perspectiva multidisciplinaria, Andorra la Vella, pp. 271-299,. 
— (2002): «El complejo sufijal -(e)sken de la lengua ibérica», Palaeohispanica 2, pp. 159-168.

Jordán Cólera, C. (1998): «Sobre los orígenes del vasco», en Schrader, C., Jordán, C. y Beltrán, J. A. (eds.), $\Delta \mathrm{t} \delta \alpha ́ \sigma \kappa \alpha \lambda \mathrm{o \zeta .} \mathrm{Estudios} \mathrm{en} \mathrm{homenaje} \mathrm{al} \mathrm{profesor}$ Serafin Agud con motivo de su octogésimo aniversario, Zaragoza, pp. 3-30.

- (2004): Celtibérico, Zaragoza.

Karmio, J. (1975): «The ousting of Etruscan by Latin in Etruria», en Brun, P. (ed.), Studies in the romanization of Etruria, Acta Instituti Romani Finlandiae, Roma, Bardi Editore, pp. 89-24.

Marques de FARIA, A. (2000): "Onomástica paleo-hispânica: revisão de algumas leituras e interpretações», Revista portuguesa de Arqueologia 3, 1, pp. 121-151.

MichelenA, L. (1961): «Los nombres indígenas de la inscripción hispanorromana de Lerga», Príncipe de Viana, pp. 65-74.

Rodríguez Ramos, J. L. (2001-2002): «Okelakom, Sekeida, Bolśken», Kalathos 2021 , pp. $429-434$.

Untermann, J. (1975): Monumenta Linguarum Hispanicarum I. Die Münzlegenden, Wiesbaden.

- (1980): Monumenta Linguarum Hispanicarum II. Die Inschriften in iberischer Schrift aus Südfrankreich, Wiesbaden.

— (1990): Monumenta Linguarum Hispanicarum III. Die iberischen Inschriften aus Spanien. Wiesbaden.

- (1993-1994): «Comentario a la inscripción musiva de Andelos», Trabajos de Arqueología Navarra 11, pp. 127-129.

- (1995): «Epigrafía indígena y romanización en la Celtiberia», en Beltrán, F. (ed.), Roma y el nacimiento de la cultura epigráfica en occidente, Zaragoza, pp. 197-208.

— (1996): «La frontera entre las lenguas ibérica y celtibérica en las provincias actuales de Zaragoza y Teruel», en VV.AA., Homenaje a Purificación Atrián, Teruel, pp. 177-189.

- (1997): Monumenta Linguarum Hispanicarum IV. Die Tartessischen, keltiberischen und lusitanischen Inschriften, Wiesbaden.

VelazA, J. (1995): «Epigrafía y dominios lingüísticos en territorio de los vascones», en Beltrán, F. (ed.), Roma y el nacimiento de la cultura epigráfica en occidente, Zaragoza, pp. 209-218.

- (1996): «Chronica epigraphica iberica: hallazgos de inscripciones ibéricas en Levante, Cataluña, Aragón y Navarra (1989-1994)», en Villar, F. y D’Encarnação, J. (eds.), La Hispania prerromana. Actas del VI Coloquio sobre lenguas y culturas prerromanas de la Península Ibérica (Coimbra, 13-15 de octubre de 1994), Salamanca, pp. 311-337.

- (1996): Epigrafía y lenguas ibéricas, Madrid, Arco/Libro.

- (2001): "Chronica epigraphica iberica II. Novedades y revisiones de epigrafía ibérica», en Villar, F. y Fernández Álvarez, Mํㅗ P. (eds.), Religión, Lengua y Cultura Prerromanas de Hispania. Actas del VIII Coloquio sobre Lenguas y Culturas Prerromanas de la Península Ibérica (Salamanca, 11-15 de mayo de 1999), Salamanca, pp. 639-662.

- (2006): "Crónica de epigrafía antigua de Navarra (II)», en Andreu Pintado, J. (ed.), Navarra en la Antigüedad. Propuesta de Actualización, Pamplona, pp. 49-75. 
- (en prensa): «En busca del texto vasco más antiguo», Congreso de Aramaiona.

Vicente, J. y otros (1993): «Las inscripciones de la Casa de Likine (Caminreal, Teruel)», en Untermann, J. y Villar, F. (eds.), Lengua y cultura en la Hispania prerromana. Actas del V Coloquio sobre lenguas y culturas prerromanas de la Península Ibérica (Colonia, 25-28 de Noviembre de 1989), Salamanca, pp. 747-772.

Villar, F. (1999): «Hispanocelta o celtibérico», en Polomé, E. C. y Justus, C. F. (eds.), Language change and typological variation: in honor of W. P. Lehmann on the occasion of his 83rd birthday, Vol. I, Journal of Indo-European Studies, Monograph number 30, pp. 60-77.

- (2000): Indoeuropeos y no indoeuropeos en la Hispania Prerromana, Salamanca.

- (2002): «El topónimo de la ceca Bentia y la lengua de los Vascones», en Crespo Ortiz de Zárate, S. y Alonso Ávila, A. (eds.), Scripta antiqua in honorem Ángel Montenegro Duque et José María Blázquez, Valladolid, pp. 183-194.

- (2005): «Indoeuropeos y euskaldunes en el País Vasco y Navarra. Genes, lenguas y topónimos», en Villar, F. y Prósper, B. Vascos, celtas e indoeuropeos. Genes y Lenguas, Salamanca, pp. 365-514.

Villaronga, L. (1994): Corpus nummum Hispaniae ante Augusti aetatem, Madrid.

Wodtкo, D. (2000): Monumenta Linguarum Hispanicarum V.1. Wörterbuch der keltiberischen Inschriften, Wiesbaden. 
